\title{
Editorial
}

\section{Dossiê Geografias dos Sons e Literatura}

As relações entre o NEPEC e as pesquisas sobre música e literatura no campo da geografia humana já são longevas e bastante consolidadas. Desde as primeiras edições do Simpósio Internacional sobre Espaço e Cultura diversos trabalhos apresentados traziam as dimensões espaciais de manifestações musicais e literárias como objeto de investigação. Nas edições mais recentes do simpósio, os Grupos de Trabalho sobre Música e Literatura têm se destacado não apenas pelo volume e qualidade de trabalhos enviados, como também pela diversidade na natureza das investigações.

Nas páginas da E\&C música e literatura também se fizeram presentes já nas primeiras edições (MESQUITA, 1997; BASTOS, 1998). Ainda em 1998, na edição de número 6, Roberto Lobato Corrêa publica "Geografia, Literatura e Musica Popular: uma Bibliografia” (CORRÊA, 1998), ofertando para os leitores uma revisão de fontes abrangente sobre o estudo destas práticas. Na bibliografia selecionada por Corrêa dois autores merecem destaque com publicações sobre literatura e música na primeira metade dos anos 1990. O geógrafo norte-americano George O. Carney, com o seu tex to “The Geography of Music” publicado no Journal of Cultural Geography em 1990, e o também geógrafo e francês Marc Brosseau, com o seu "Geography as Literature" publicado na Progress in Human Geography em 1994. Ambos evidenciavam em suas obras que o interesse pelas dimensões espaciais dessas práticas artísticas não era exclusividade da geografia brasileira. 
A coleção de livros Geografia Cultural, publicada pela EdUERJ, e organizada pelos fundadores do NEPEC, editores da E\&C e organizadores do Simpósio Internacional sobre Espaço e Cultura, Zeny Rosendahl e Roberto Lobato Corrêa, também teve exemplares dedicados ao debate sobre esses objetos de estudo. Em 2007, no livro "Geografia, Literatura e Música" (CORREA e ROSENDAHL, 2007), Carney e Brosseau foram devidamente traduzidos e introduzidos para o leitor brasileiro. Dois textos de Brosseau sobre geografia e literatura e um texto de Carney sobre música e lugar ganharam versões em português e intensificaram a circulação desses autores entre pesquisadores de diferentes níveis nas universidades brasileiras. Cotejando referências nacionais e estrangeiras a análise de obras literárias e a geografia da música ganharam força na geografia cultural e nas páginas da $\mathrm{E} \& \mathrm{C}$ nas últimas décadas, resultando em uma série de trabalhos criativos e relevantes para se pensar esses objetos de estudo (e.g VILANOVA NETA 2004; FERNANDES 2013; FERREIRA 2016; NUNES, 2017).

Embora o campo da geografia cultural tenha seu papel em congregar estudiosos interessados na geografia da música e na literatura, é importante ressaltar que o estudo deste objeto é anterior a chamada virada cultural que o campo experiencia a partir dos anos 1980. É o que evidencia o geógrafo Lucas Manassi Panitz (UFRGS) no texto "Redes Musicais e (Re)Composições Territoriais no Prata: por uma geografia da música” que abre a presente edição da E\&C. Segundo Panitz, o interesse da geografia pela música tem origens mais remotas, passando pelo discípulo de Friedrich Ratzel, Leo Frobenius, que estudou a morfologia dos tambores e pelo geógrafo da escola dos Annales na França, Georges Gironcourt, que propôs "nominalmente” uma "geografia musical”.

Apesar dessa ressalva, é notório o incremento do conhecimento produzido, seja na forma de artigos, coletâneas ou encontros científicos, sobre esses fenômenos nas últimas três décadas. Ao citar trabalhos organizados pela geógrafa de Cingapura Lily Kong, pelo geógrafo britânico Andrew Leyshon, pelo geógrafo francês Jacques Lévy entre outros, Panitz sublinha o crescente interesse pelo campo a partir dos anos 1990. 
Buscando entender como se deu o processo de formação de algumas das atuais redes musicais transfronteiriças entre Argentina, Brasil e Uruguai, Panitz advoga pela necessidade de um trabalho etnográfico que participe do fluxo, "seguindo pessoas, objetos e ideias, registrando os contextos de circulação e suas transformações no tempo e no espaço”. É por meio de uma pesquisa etnográfica "multilocalizada" que o autor revela uma produção fonográfica transfronteiriça de caráter transterritorial.

A atração pela música entre as geógrafas e os geógrafos brasileiros se difundiu entre pesquisadoras e pesquisadores do campo. É o que sugere o geógrafo Alessandro Dozena (UFRN) em "Os Sons como Linguagens Espaciais" nessa edição da E\&C. Dozena reconhece como os trabalhos focados na música entre as geógrafas e os geógrafos brasileiros se basearam em "escritos em francês e inglês" que foram publicados principalmente após a “virada cultural” na disciplina na década de 1980. Para além dos debates no âmbito internacional, Dozena aponta o surgimento no Brasil de novos temas, noções e abordagens que têm contribuído para ampliar o entendimento da música e do som enquanto espacialidade e territorialidade, possibilitando investigações de uma maior variedade de fenômenos sonoros.

O interesse pela circulação, assim como em Panitz, se faz presente no ensaio de Dozena, que defende uma perspectiva onde os sons são entendidos como "linguagens espaciais" que se deslocam no espaço comunicando ideias e sentimentos. Ao ouvir a música o indivíduo também “ouve o território” e devemos considerar como a globalização tem papel fundamental na "divulgação dos sons e estilos musicais de diferentes localidades, contribuindo com a configuração de territórios musicais híbridos”.

Dozena advoga por uma "escuta ativa” do pesquisador como um elemento importante e se refere a "sons e música" "com a intenção de abarcar a plenitude de possibilidades sonoras”. Segundo o autor a música seria uma "combinação harmoniosa e expressiva de sons, um conjunto de sons vocais, instrumentais ou mecânicos com ritmo, harmonia e melodia”. Contrastando com um enfoque nessa "combinação harmoniosa”, muitos trabalhos contemporâneos pertencentes ao que o autor chama de um "movimento 
etnogeográfico", estariam mais interessados em explorar as experiências sonoras, destacando práticas e ruídos de diferentes naturezas.

Os dois artigos que se seguem na presente edição da E\&C também estão inseridos no contexto da consolidação e renovação dos estudos sobre música na geografia brasileira, uma vez que ao mesmo tempo se ancoram e desafiam as formas clássicas de estudo da música e dos sons na disciplina. Neste sentido, percebemos três pontos de convergência que parecem arejar as abordagens sobre geografia e música nos trabalhos aqui reunidos: a circulação, a escuta e a vivência. Ao invés de focarem na sutura simbólica entre música e lugar, evidenciando como a música atribui significado a porções específicas do espaço, os trabalhos aqui reunidos demonstram um enfoque bastante consistente na circulação.

No texto "Performance e Música: possibilidades de trocas afetivas e de ocupação do espaço público no festival ativista de fanfarras HONK! Rio 2018” o geógrafo natural da França, doutorando em geografia Michel Moreaux (PPGEO/UERJ) também destaca a circulação e o encontro como elementos fundamentais para uma geografia focada na dimensão sonora. Em sua pesquisa sobre o festival de fanfarras ativistas que ocupou diversas ruas da cidade do Rio de Janeiro em novembro de 2018, o autor busca explorar um "tipo de encontro presencial entre participantes de fanfarras oriundas de cidades e países diferentes". É por meio do encontro entre diferentes trajetórias que Moreaux considera como o diálogo entre os artistas pode gerar um aprimoramento das performances durante o festival.

A pesquisa de Moreaux está focada não nas letras ou significados específicos das músicas, mas sim na experiência performáticas do público e dos artistas ao praticarem música nas ruas da cidade do Rio de Janeiro. Assim, é um trabalho que pode ser inserido em uma perspectiva "etnogeográfica”, mencionada por Dozena, uma vez que pratica uma escuta ativa para trabalhar com os sons no contexto urbano.

A escuta se revela o segundo ponto de convergência dos trabalhos aqui reunidos. Em detrimento do foco na "musica" como um produto pronto e finalizado, são os "sons" que abrem caminhos de pesquisas que elegem a ESPAÇO E CULTURA, UERJ, RJ, N. 45, P.03-10, JAN./JUN. DE 2019 http://www.e-publicacoes.uerj.br/index.php/espacoecultura/ 
"escuta" como um procedimento metodológico fundamental. O enfoque nos "sons" é bastante marcante no texto "O Trabalho de Campo na Geografia: características fundamentais e um convite à escuta" do geógrafo e doutorando Renato Coimbra Frias (PPGG/UFRJ), que após discutir as especificidades do trabalho de campo na geografia, busca oferecer conceitos e práticas de campo que podem auxiliar no planejamento de uma investigação empírica priorizando a dimensão sonora. Contrastando com uma tradição ocularcentrista na história da disciplina, Frias defende que o som é tanto a expressão quanto o meio de diferentes modos de interação e organização da vida social e, portanto, deve ter um tratamento metodológico específico no trabalho de campo de geógrafas e geógrafos.

O terceiro ponto de convergência diz respeito às vivências, experiências e relações com a música dos quatro pesquisadores aqui reunidos nessa primeira seção da revista. Panitz, Dozena, Moreaux e Coimbra estudam e vivenciam sons e músicas. Lucas Manassi Panitz é músico violonista, integra a banda Apóstrofes e participa ativamente de projetos em redes musicais transfronteiriças entre Argentina, Brasil e Uruguai. Dozena é músico formado pela Universidade Livre de Música em São Paulo, tem intensa inserção no universo musical e participou de um dos grupos mais importantes de percussão corporal no Brasil, os Barbatuques de São Paulo. No intuito de evidenciar o poder da música para estreitar as interações sociais, fortalecer os vínculos comunitários e as práticas de sociabilidade, o próprio autor ressalta a sua "experiência anterior com a Orquestra Orgânica Performática”.

Michel Moreaux é músico e integra a banda Bagunço com seu sax alto, pife e clarinete. O Bagunço é uma banda que compõe a cena musical independente carioca se apresentando frequentemente no espaço público da cidade do Rio de Janeiro. Em seu trabalho de campo o autor deixa claro que além de uma observação e uma escuta ativa, o mesmo também "tocou junto" com os entrevistados, posição que altera profundamente a sua inserção e a sua abordagem para trabalhar com as relações entre performance e espaço. Logo nas primeiras linhas do seu artigo, o autor explicita que "esse trabalho surge 
através do meu envolvimento inicial, como músico, em algumas fanfarras e coletivos do Rio de Janeiro".

Renato Coimbra Frias é músico guitarrista e atuou como DJ Dom Coimbra no Baile do Bené, festa que faz parte da cena cultural da cidade do Rio de Janeiro, que congrega diferentes expressões artísticas do movimento black, funk e charme. Muito conectado ao universo da discotecagem, Frias tem intimidade com os equipamentos sonoros o que explica o seu profundo interesse pela tecnologia de registros e gravações durante os trabalhos de campo. Fruto desse interesse foi a criação de conta em plataforma online de publicação de áudio na qual compartilha registros de diferentes espaços públicos da cidade do Rio de Janeiro.

A circulação, a escuta e a vivência no universo sonoro, portanto, são elementos que oxigenam o campo de estudo dos sons na geografia brasileira. Embora a literatura tenha sido utilizada mais frequentemente para descrever os aspectos paisagísticos e simbólicos dos lugares, novos caminhos também surgem nos estudos dedicados a literatura que fecham esse número da $\mathrm{E} \& \mathrm{C}$. Uma abordagem bastante interessante se faz presente no tex to "Narrativas em Diálogo: imbricações geográficas, literárias e educacionais entre A Geografia de Dona Benta (1935) e Le tour de la France par deux enfants (1877)" do geógrafo e doutorando em educação Filipe Rafael Gracioli (UNESP - Rio Claro) e do também geógrafo e professor do Departamento de Educação João Pedro Pezzato, (UNESP - Rio Claro). Os autores propõem comparações e entrelaçamentos entre as obras literárias presentes no título do texto. Ao buscar identificar os diálogos entre as narrativas do escritor brasileiro Monteiro Lobato e da escritora francesa Augustine Fouillée sob o pseudônimo de G. Bruno, Gracioli e Pezzato procuram analisar a natureza geográfica das obras direcionadas ao público infantil. O universo da "criança leitora", menos explorado no campo da geografia cultural, é objeto de estudo enfocando, segundo os autores, "um tipo de escrita que inaugura para a infância uma literatura de itinerário, unindo literatura e geografia de modo jamais visto na escrita orientada à criança no ocidente”. 
Propondo trabalhar com a metodologia de Ginzburg do paradigma indiciário, que busca revelar indícios nos textos que podem dar luz a aspectos frequentemente negligenciados, os autores exploram a hipótese de que Monteiro Lobato tenha se inspirado no livro francês para desenvolver a sua narrativa. Nesse sentido a circulação na literatura não estaria apenas presente nos textos analisados, que revelam uma literatura de itinerário com muitos aspectos geográficos e históricos, mas também na relação entre os textos, evidenciando como uma obra feira em um contexto diverso, como o francês, pode influenciar narrativas clássicas na história da literatura brasileira. Visto de forma relacional e contextual as obras literárias deixam de representar cristalizações e suturas atemporais de significados aos lugares e podem revelar contra narrativas e contingências específicas de produção.

Encerra a edição o texto "Um sertão cheio de vazios: leituras geográficas da Pedra do Reino” assinado pelo futuro geógrafo Ariel Roemer (USP) e por Manoel Fernandes de Sousa Neto, professor Livre Docente do Departamento de Geografia (USP). O artigo propõe uma leitura geográfica do "Romance da Pedra do Reino e O Príncipe do Sangue do Vai-e-Volta", de Ariano Suassuna.

Contrastando com uma abordagem puramente descritiva ou focada na construção de um imaginário estereotipado sobre o sertão, os autores do tex to exploram a trajetória biográfica de Suassuna para evidenciar como em seu romance há um esvaziamento da relação de alteridade com este espaço. Para além de um sertão estranho, um espaço do “outro”, novas descrições emergem na narrativa onde o literato tem sua própria história como referencial. Explorando os conceitos de carnaval e cronótopo de Bakthin, Roemer e Sousa Neto buscam sistematizar caminhos frutíferos para as análises literárias, onde as dimensões espaço-temporais focam nas transformações históricas que tornariam impossível qualquer descrição das paisagens como uma “naturalidade autossuficiente”. É a partir dessas referências que os autores conseguem revelar um outro sertão na obra de Suassuna, produzindo "uma mudança de perspectiva no olhar" onde para além de um espaço distante, o sertão ganha dinamicidade e centralidade em sua própria história. 
Se a música, os sons e a literatura já fazem parte do temário das geógrafas e dos geógrafos há bastante tempo, acreditamos que esta edição da $\mathrm{E} \& \mathrm{C}$ pode oferecer mais uma contribuição às perspectivas teóricas, metodológicas e empíricas aplicadas às investigações de fenômenos sonoros e textuais.

Desejamos a todas e a todos uma boa leitura!

Mariana Lamego

André Reyes Novaes

\section{REFERENNCIAS SONORAS}

Lucas PANITZ. Sobre a banda Apóstrofes: https://bandaapostrofes.wordpress.com/

Michel MOREAUX. Sobre a banda Bagunço: http://bagunco.com

Renato Coimbra Frias. http://soundcloud.com/ouvindolugares

\section{REFERÊNCIAS BIBLIOGRÁFICAS}

BASTOS, Ana Regina Vasconcelos Ribeiro (1998). Espaço e Literatura: algumas reflexões teóricas. Espaço e Cultura, n.5, jan-jun, pp. 55-66.

CORREAA, Roberto Lobato (1998). Geografia, Literatura e Música Popular: uma bibliografia. Espaço e Cultura, n.6, jul-dez, pp.59-65.

CORREAA, Roberto Lobato e ROSENDAHL, Zeny (2007). (Orgs). Literatura, Música e Espaço. Rio de Janeiro: EdUERJ. (ColeçãoGeografia Cultural)

FERNANDES, Felipe Moura (2013). Geografia e Literatura (Ciência e Arte): proposições para um diálogo. Espaço e Cultura, n.33, jan-jun, pp. 167-176.

FERREIRA, Marta Martines (2016). Viola-de-Cocho Pantaneira: história e memória. Espaço e Cultura, n.40, jul-dez, pp.99-112.

MESQUITA, Zila (1997). A Geografia Social na Música do Prata. Espaço e Cultura, n.3, janjun, pp.33-41.

NUNES, Rafael da Silva (2017). Leituras do Poder na Terceira Era da Terra-Média: um ensaio baseado em O Senhor dos Anéis. Espaço e Cultura, n.41, jan-jun, pp.148-166.

VILANOVA NETA, Maria Amélia (2004). Decifrando o espaço a partir da literatura. Espaço e Cultura, n.17-18, jan-dez, pp.107-118. 